\title{
EVIDENCE OF DESIGN IN BIRD FEATHERS AND AVIAN RESPIRATION
}

\author{
A.C. McINTOSH \\ Energy and Resources Research Institute, University of Leeds, Leeds, UK.
}

\begin{abstract}
Editor's Note: This paper presents a different paradigm than the traditional view. It is, in the view of the Journal, an exploratory paper that does not give a complete justification for the alternative view. The reader should not assume that the Journal or the reviewers agree with the conclusions of the paper. It is a valuable contribution that challenges the conventional vision that systems can design and organise themselves. The Journal hopes that the paper will promote the exchange of ideas in this important topic. Comments are invited in the form of 'Letters to the Editor'.
\end{abstract}

\section{ABSTRACT}

This paper explores the evidence for design in living systems. In particular, it considers two of the mechanisms used in bird flight. These include feathers and the remarkable counterflow mass exchanger breathing system used in the avian lung system. Both systems are examples of the principle of specified functional complexity, which occurs throughout nature. There is no known recorded example of this developing experimentally where the precursor information or machinery is not already present in embryonic form. Such design features indicate non-evolutionary features being involved.

Keywords: avian respiration, birds, design, evolution, feathers, lungs, nature.

\section{INTRODUCTION}

Many have taken the view that design is only an illusion in living systems [1], arguing that such 'apparent design' and accompanying complexity can be explained by the neo-Darwinian paradigm. However, such thinking fails to realise that functional systems, in order to operate as working machines, must have all the required parts in place in order to be effective. If one part is missing, then the whole system is useless. The inference of design is the most natural step when presented with evidence such as in this paper, that is evidence concerning avian feathers and respiration. The counter argument has often been made that functional complexity can appear from simpler systems which evolve over time. However there has never been a recorded observation of this happening experimentally in the laboratory (where the precursor information or machinery is not already present in embryonic form). Though it is true that a design action is also not observed in the laboratory, nevertheless the inference to original design and intelligence is a perfectly valid alternative from direct analogy to designs within the man-made world. Even though specified functional complexity has not been experimentally observed to develop from simpler systems, this has not deterred the stridency with which such views are put forward by some of evolution's proponents. In particular, the arguments seeking to align such thinking with the principles of thermodynamics lead to, at best, speculative ideas to explain how these fundamental structures and information emerge. The powerful fundamental arguments from thermodynamics actually favour the straightforward view that such organisational structures cannot appear without pre-existing functional complexity being there to begin with [2,3]. Though this matter is referred to again in Section 2.4.3 below, the accessibility of such arguments is perhaps difficult for the non-specialist, particularly as rhetoric can cloud the actual scientific facts. Therefore, the main intention in this paper is to draw attention to machinery which can readily be understood by most readers with some scientific background, and to appreciate some of the features which defy an explanation by slow gradual changes, as required by neo-Darwinian evolution. 
One last point which is important to make in this introduction is the nature of the scientific debate itself. It needs to be stated clearly that origins science, though it clearly has philosophical implications, is nevertheless a genuine scientific debate. It is not the prerogative of science to make statements beyond the remit of the study of natural systems, since by its very nature, science can only be the study of the material world. Consequently, to try and assert that natural systems can only ever have come about by a preexisting natural system without intelligence is an unproven assumption, and must immediately be recognised as such. To take only natural causes as one's starting point seems innocuous enough, for some would say that does it not helpfully separate 'religious' questions from 'scientific' ones? Surely 'here is the way forward' say a large group of scientists, most of whom have no predisposition to be either for or against any particular philosophical view of reality. They just wish to pursue the science. However, what is a useful and pragmatic way forward, for taxonomic purposes, of describing rich, living biological systems, becomes totally inappropriate when looking at the origins of such systems, since to deny the possibility of the involvement of external intelligence is effectively an assumption in the religious category [4]. Science can study the effect on the natural world of systems of pre-existing material, but it cannot preclude the possibility of intelligence extraneous to that very matter and energy being involved in its formation. To say otherwise is effectively wedding science to a narrow philosophical foundation.

We quote here the important statement of a great thinker and evolutionist - Stephen Jay Gould [5], who often spoke against the position that there is necessarily an intelligence behind the design observed in nature:

Moreover, 'fact' does not mean 'absolute certainty.' The final proof of logic and mathematics flow deductively from stated premises and achieve certainty because they are not about the empirical world. ... In science, 'fact' can only mean 'confirmed to such a degree that it would be perverse to withhold provisional assent. I suppose that apples might start to rise tomorrow, but the possibility does not merit equal time in physics classrooms.

Gould is right that logic and mathematics flow from stated premises, and it is that very point that we seek to emphasise here. Once one opens the possibility that intelligence is involved, the evidence leads very naturally to the conclusion of design, not by going against the known empirical laws (such as gravity in the analogy of Gould), but precisely the reverse. We must keep to the 'nullius in verba' motto of the Royal Society ('on the words of no one'), and not preclude from the outset where the evidence may lead.

\section{FEATHERS}

\subsection{Types of feathers}

Feathers are of different types depending on location. The major types of feathers are illustrated in Fig. 1, which shows that there are at least five different types.

Flight feathers are mainly the primary feathers on the outer part of the wing. These and the tail feathers are together called remiges. The primary feathers are larger in size relative to the other feathers, and asymmetric in shape. As the name implies, they bear the greatest aerodynamic load, and without them, a bird will not be able to fly. These are often the feathers cut in order to train a bird. They will, of course, regrow, but a bird is helpless without them. The secondary feathers are needed to complete the inner part of the wing and maintain stability. Those closest to the body of the bird are called the tertiary feathers. The base of the flight feathers are also covered by smaller feathers called covert feathers. These also thicken the leading edge of the wing such that an aerofoil shape is maintained in cross section by the extended wing. All the above are called pennaceous feathers as they have closely connected barbs 


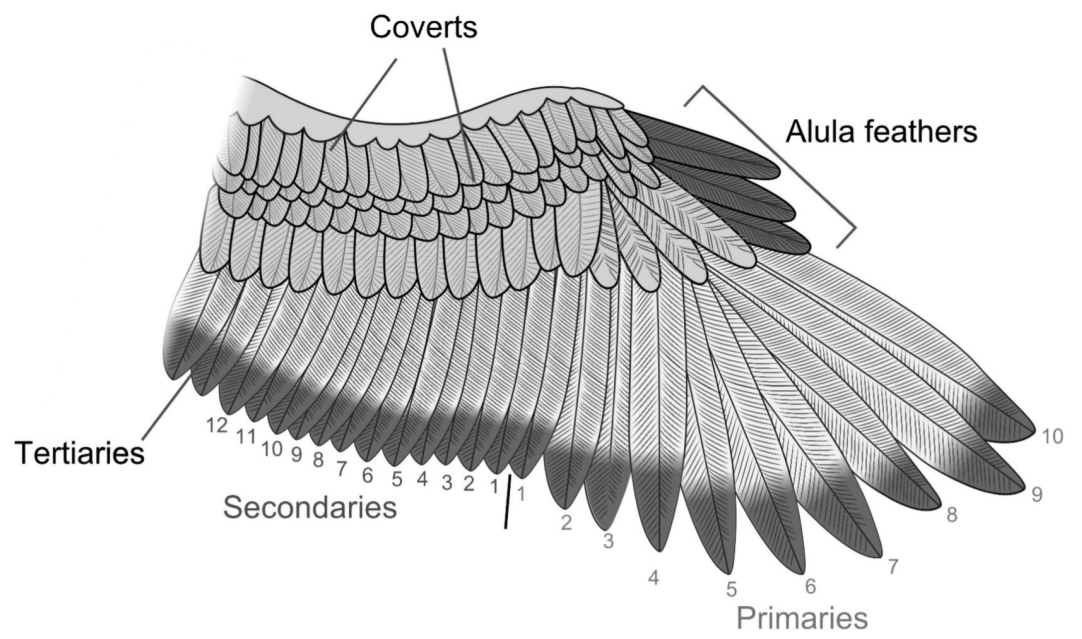

Figure 1: Different types of feathers.

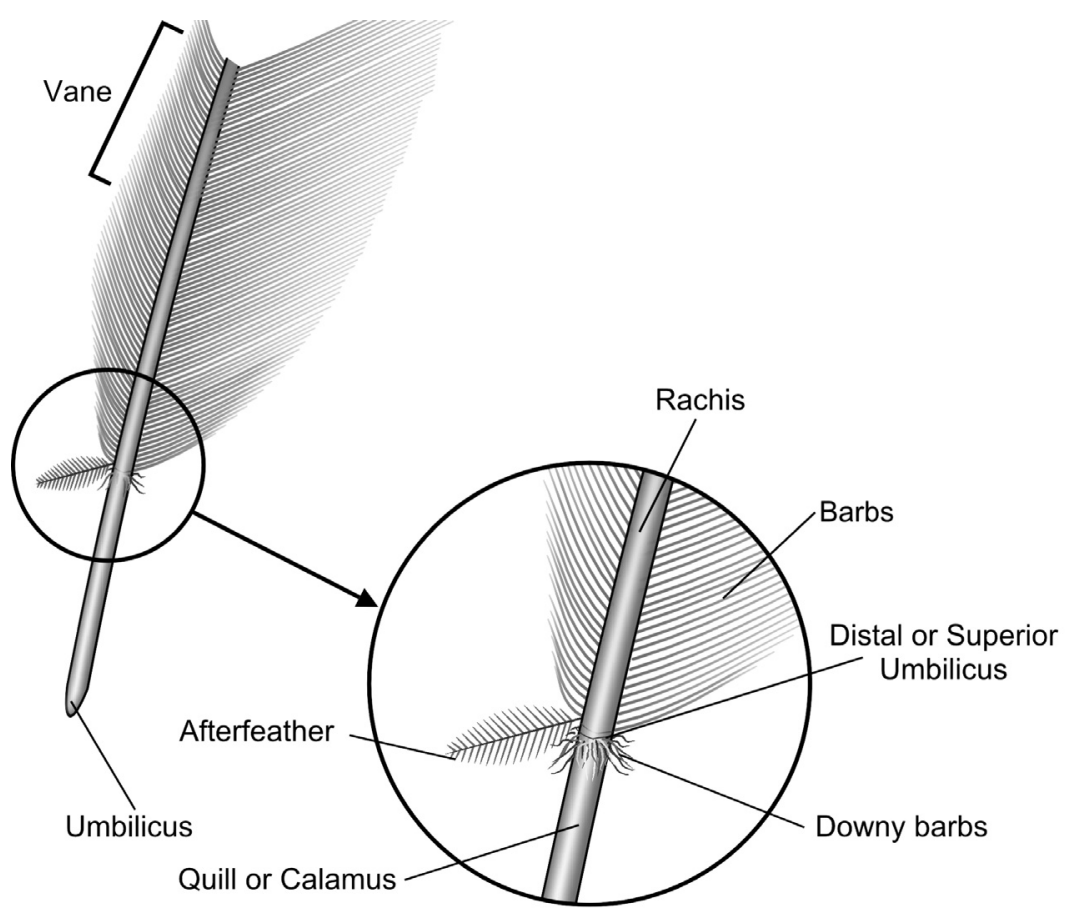

Figure 2: Detail of barbed feather.

and form aerodynamic surfaces. There are other feathers which are called plumulaceous, or downy, feathers. These have only a rudimentary rachis and a jumbled tuft of barbs with long barbules to provide an excellent thermal insulation. The details of a feather are shown in Fig. 2.

Not shown in Fig. 1 are the tail feathers (retrices) which have a symmetrical shape but are designed for use as air brakes and also control the direction of flight. 
One of the most easily overlooked feathers are those forming the alula (or alular) grouping essentially a set of finger feathers on the leading edge of each wing of a bird. These feathers are crucial because, for low speed flight, they act as a leading edge slat and keep the boundary layer attached across the upper surface of the wing that is formed from the main primary, secondary and tertiary pennaceous feathers. The alula group of feathers are attached to a projecting digit coming from the humerus bone. This digit is called the pollex and acts rather like the human thumb. The number of alula feathers attached to the pollex depends on the species. The humming bird has two, the cuckoo has five or six, and there can be as many as seven. Without these small feathers, the control of flight would be extremely difficult at low speed.

\subsection{Hook and ridge barbule arrangement of feathers}

Feathers are made of keratin, a protein also used to make hair and fingernails. There are differences in the exact type of keratin used. Feather keratin occurs in a ' $\beta$-sheet' configuration, which differs from the $\alpha$-helices that generally occur in mammalian keratins [6]. The $\beta$ keratin of bird feathers is rather like a stretched spring in consistency. The fact that scales of reptiles are also made of keratin is used by some to propose that dinosaurs are the precursors to birds. However, it should be noted that there are significant hurdles to transform one type of keratin to the other [7]. The feather grows from a follicle, and from the central rachis come barbs which give the vane of the feather.

The details of the sophistication involved in the barb system of the pennaceous feather become clear under a microscope. In Fig. 3, barbules can be seen coming from each barb. They are only visible at the micro level, but have a structure that is essential for feathers to work as aerodynamic surfaces. The barbules in one direction are ridge-like, while the barbules in the opposing direction have hooks. Consequently, the hooks of the barbule in one direction grip the ridge of the opposing barbule. Figure 4 shows further details of this remarkable arrangement.

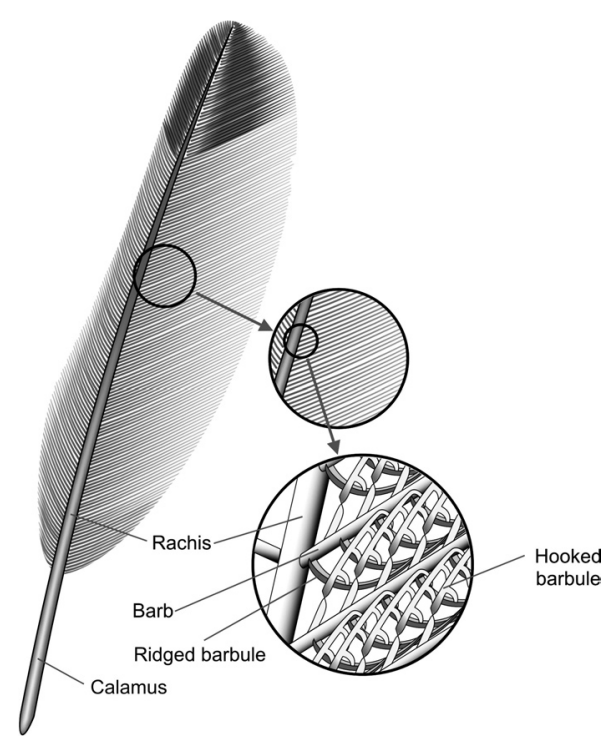

Figure 3: The hooked and ridged structure of barbules in a pennaceous feather. 

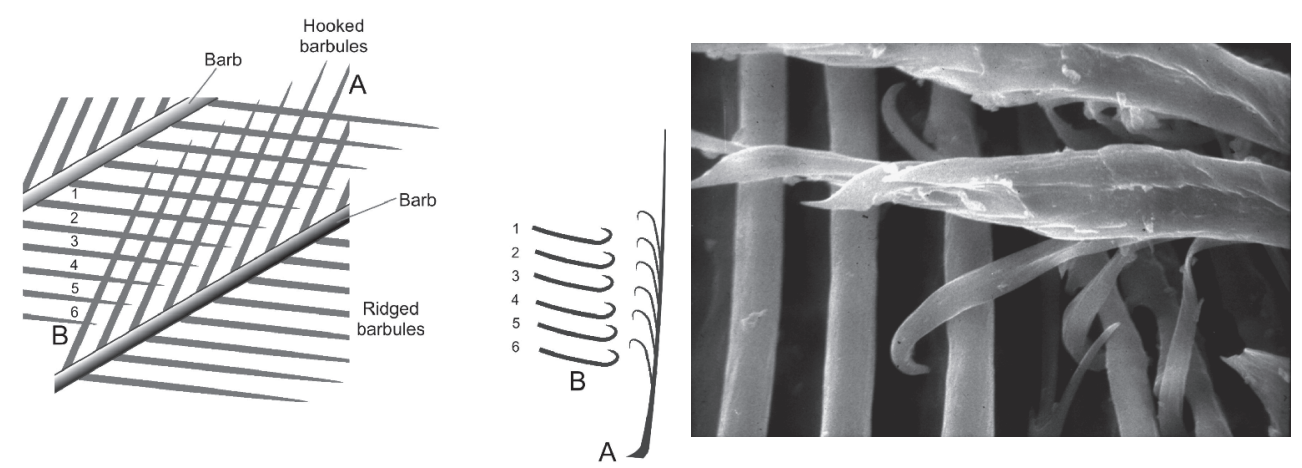

Figure 4: Detail of hook and ridge system for pennaceous feather barbules. Source: Photograph courtesy of Prof. David Menton, Washington University School of Medicine, St. Louis, Missouri.

\subsection{Keratin sheath of feathers}

Feathers grow from follicles and are made from multilayered keratinocyte sheets [8]. As already noted, the feather keratin is in a $\beta$-sheet configuration and develops within the follicle which supports, in the initial stages of growth, a cone arrangement made from a rachidial ridge (which becomes the rachis in the fully developed feather) and the barbs curled round with a longer circumference at the base of the cone and shorter barbs forming the tip. All this is enclosed in a keratin sheath, the lining of which is connected to the follicle as a single layer.

As the plumage appears, at each feather follicle, the cone becomes a sheath and then gives way to the feather as it emerges from the vertex. These sheaths become tube-like and are present for any new feather. This will be the case for adults, as feathers are replaced in moulting, but are more visible and noticeable in a fledgling (see Fig. 5) since all the feathers are then developing together and emerge from the vertex of their coned follicles into individual separate tubes of keratin. These tubes run the length of each feather, thus protecting the delicate feather barbs as they develop in the

(a)

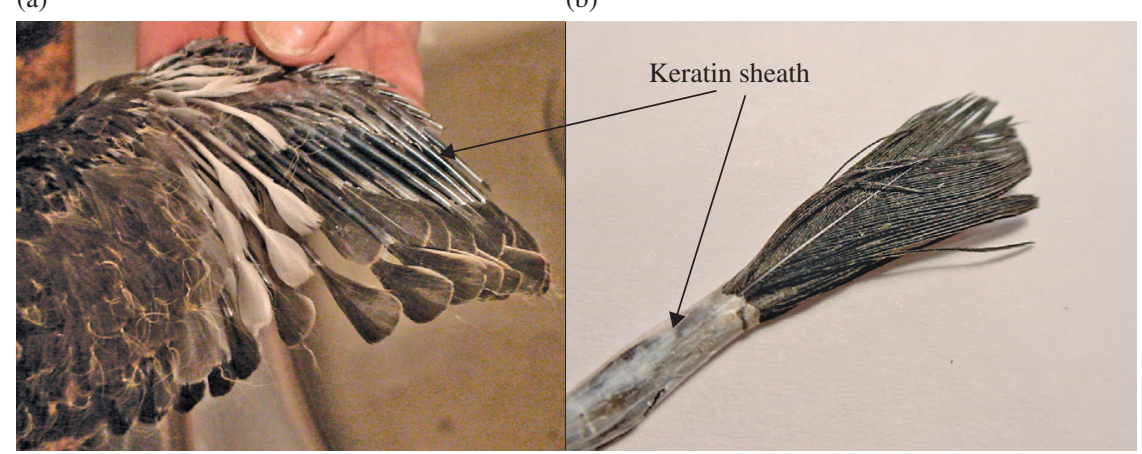

Figure 5: (a) Wing of a fledgling pigeon showing feathers still sheathed. (b) Sheathed feather from fledgling rook. The sheath is made of keratin and is connected to the follicle. 
embryo within the egg. The final emergence of the feathers in a fledgling can take a few weeks for these to unfold and the keratin sheath to break away - see Fig. 5.

\subsection{Design features of feathers}

King and McLelland [9] and Burgess [10] have shown that there is multifunctioning and multioptimisation in feather construction. There are the features which are immediately apparent such as aerodynamic loading and the material construction of rachis and barbs to sustain this. However, there are also more subtle features such as the arrangement of hooks and barbules primarily for keeping the feather together, such that they prevent air from going through them during the downstroke but allowing some air to pass through in the upstroke, thus maximising the efficiency of energy use in wing flap. The keratin itself has an extremely high specific strength, and the shape of the filament cross sections used in rachis construction moves from near circular near the root to a curved and ribbed rectangular shape away from the root for structural efficiency under bending and potentially buckling loads. The evidence is consistent with the design thesis both from the fossils found of flight in the past, and in the multifunctional nature of wings today.

\subsubsection{Fossil evidence}

It is evident that the hook and ridge system is a key feature of the barbule system connecting the barbs of a feather. How this came about has been the subject of a number of speculative conjectures in the scientific literature [11-13]. Laudable indeed have been the attempts to find the evolutionary engine to provide specific function, but the attempt is not impressive, since the array of simpler structures is difficult to imagine, let alone find in the fossil record. Prum [12] takes the view that the forerunner of the pennaceous feather could have been a conical papilla similar to a hair arising out of a cylindrical follicle within the skin. It is then proposed that the papilla became a tuft of barbs (unbranched filaments), and then each of these filaments eventually branched into the barbules. And then, finally, it is maintained that the branched filaments became organised around a central stem (rachis) to produce the hook and ridge structure of present-day feathers. However, the real issue is not addressed by any of these studies. By definition, the Darwinian evolutionary 'mechanisms' (which Dawkins summarised as 'non-random survival of randomly varying hereditary instructions for building embryos ...' [1]) have no sense of overall future gain other than the immediate next step. These authors look for evidence that true feathers developed first in small non-flying dinosaurs before the advent of flight, possibly as a means of increasing insulation for the warm-blooded species that were emerging. Though attempts have been made to suggest that the Liaoning shales in Northeast China provide evidence of early feathers on dinosaurs, the hard evidence of clear examples of an intermediate intricate barbule system (hook and ridge) in the vanes has not yet been produced. Xu et al. [13] refer to structures made from filaments of skin in fossils of Sinornithosaurus millenii, a non-avian theropod dinosaur in sediments that are classically dated as about 125 million years old. Though there is evidence of a downy structure, flight feathers were not apparent. What is actually known from the hard fossil evidence (rather than speculation) is that there certainly were now extinct creatures which also had feathers. Archaeopteryx clearly had fully developed flight feathers [14] and the species Microraptor gui $[15,16]$ shows every evidence of being simply another perching extinct bird, though the feathers are not as distinct as those in Archaeopteryx. A better example is the early Cretaceous Hongshanornis longicresta from the lower Jehol group in the Yixian formation in Northeast China. This example does have barbed feathers [17] and thus falls again into the category of an extinct bird. Thus, the actual evidence shows that one either has extinct fully developed feathers (Archaeopteryx, Hongshanornis, possibly Microraptor gui) or small reptilian 
dinosaurs such as Sinornithosaurus millenii. A clear example of an in-between transitional stage is missing.

It should also be noted that to maintain aerodynamic versatility, pennaceous feathers have to be maintained airworthy. This is done by a bird obtaining oil from the uropygial (preening) gland at the base of its spine. The ability to reach this gland is a feat of twisting which a bird performs with ease. However, it raises serious issues concerning the supposed evolution of feathers, since it is necessary for the feather construction (barbule ridge and hook system) to arise concurrently with the preening gland and the ability to manoeuvre the neck a full 180 degrees. None of the fossil evidence shows any evidence of such transitions.

\subsubsection{Evolutionary arguments of feather morphogenesis}

Alongside the paleontological studies involving the search for clear transitional fossil evidence, there have been attempts to analyse molecular mechanisms in supposed feather-branching morphogenesis. Yu et al. [18] delivered exogenous genes to regenerate flight follicles in chickens and identified a critical protein necessary in feather branching. They suggest that this identifies molecular pathways underlying possible transformations of feathers from cylindrical epithelia to hierarchical branched structures. Two alternative routes are discussed. The first is by suggesting that the rachis evolved, then the barbs and finally the barbules. The other view of Wu et al. [19] is that barbs appeared first from supposed integument evolution, followed by a fusing of the barbs to form a rachis. However, in all these investigations, it is still speculation governing such evolutionary hypotheses, since a critical protein has yet to be identified in the formation of feathers. The reality is that there is a fully formed structure of ridged and hooked barbules in all pennaceous feathers and these are found with precise function and position in the wings of birds.

So, the rigorous examination of the evidence points rather towards functional complexity coming from intelligence - to suggest that this came about only through the workings of natural selection and random mutations is, in the view of this author, not consistent with the evidence. One of the points which is important is that it is not sufficient to simply have barbules to appear from the barbs but that opposing barbules must have opposite characteristics - that is, hooks on one side of the barb and ridges on the other so that adjacent barbs become attached by hooked barbules from one barb attaching themselves to ridged barbules from the next barb (Fig. 4). It may well be that as Yu et al. [18] suggested, a critical protein is indeed present in such living systems (birds) which have feathers in order to form feather branching, but that does not solve the arrangement issue concerning lefthanded and right-handed barbules. It is that vital network of barbules which is necessarily a function of the encoded information (software) in the genes. Functional information is vital to such systems.

\subsubsection{Functional information}

Some authors [20-25] assert that possible modes of functionality increase with the rise in 'Shannon information' (Shannon information equates with the uncertainty of states of an ensemble of microsystems) and that natural selection then selects out the functioning alternative valid for that environment. They appeal in particular to autocatalytic systems, self-organising systems and pattern formation to form primal replicators from which functional complexity then emerges as natural selection sifts the ensemble of alternatives to single out the replicator with functional advantage. Ball [26] developed these ideas and put greater detail into the arguments by showing convincingly that pattern formation arises from the autocatalytic feedback chemical systems referred to earlier. The Turing patterns in the chlorite-iodide-malonic acid reaction are an example of dissipative structures in reaction-diffusion equations. These type of non-linear systems are connected to the patterns that emerge, such as giraffe and zebra pelts. Most are of the view that he is very likely correct and this author agrees. There can 
be no doubt that the work of Murray and co-workers of many years [27-29] has done much to elucidate the role of reaction-diffusion mechanisms for formation of patterns in living systems. The well-known Turing reaction-diffusion equation predicts accurately the distribution of surface markings in animals, and the target patterns of the Belousov-Zhabotinskii chemical reaction (involving cyclic AMP, that is, cyclic adenosine monophosphate) are well simulated by the Field-Noyes mathematical model [30]. Furthermore, the periodic patterns of feather germs can also be predicted using similar mathematical principles.

However, correct and enlightening as these models are, it is important to recognise that this is not the same as functional information, where coded instructions are involved, first, in the precise ordered arrangement of nucleotides in DNA, and, secondly, in the multifunctioning construction of items from these codes such as hooked and ridged feather barbules. This is a subject of a separate paper [31] by the author where the argument is made that all living systems have coded machinery which sits on high free energy bonds, all of which have to be in place for the system to work. That is, the natural tendency is for the linkages needed for those coding systems (e.g. nucleotide bonds) to decay, and not to be sustained without prior information within the system. Thermodynamically, the very material on which the coded information sits is acting against the natural law which, were it not for the information in the system, would have it fall apart. This strongly suggests that the information, far from being thought as material, is in fact non-material (like the coded instructions of software on a computer) and itself constrains the matter and energy of the nucleotide bonds to perform as they do in DNA. This is certainly the view of other authors and a very cogent statement of this position comes at the end of the paper (conclusions) by Abel and Trevors [3]:

Reduced uncertainty (misnamed 'mutual entropy') cannot measure prescriptive information (information that specifically informs or instructs). Any sequence that specifically informs us or prescribes how to achieve success inherently contains choice controls. The constraints of physical dynamics are not choice contingent. Prescriptive sequences are called 'instructions' and 'programs.' They are not merely complex sequences. They are algorithmically complex sequences. They are cybernetic. Random sequences are maximally complex. But they don't do anything useful. Algorithmic instruction is invariably the key to any kind of sophisticated organization such as we observe in any cell. No method yet exists to quantify 'prescriptive information' (cybernetic 'instructions').

As noted earlier, Gould [5] stated 'I suppose that apples might start to rise tomorrow, but the possibility does not merit equal time in physics classrooms'. By the same logic, when stripping away interpretation and conjecture [32] from the scientific facts, and putting all the evidence on the table, the straightforward implications of the hook and ridge system is that there is functional complexity at the outset, with a purpose in view - an aerodynamic surface. Even Richard Dawkins, who is known for his strong Darwinian beliefs, when asked what it was that caused the intricate hook and ridge barbule mechanism of the feather to come about, stated 'I suppose it is a matter of faith on my part' (Brief History of Disbelief, Jonathan Miller BBC2, 14 November 2005). Such an admission shows the difficulties inherent in an explanation in purely materialistic terms of such a device. The barbules growing one way have to be of a different type to those growing in the other direction, otherwise a smoothly connected aerodynamic surface cannot be achieved. Also, one cannot have a mixed distribution of hooked and ridged barbules on one side of the barb. They must of necessity be ridged entirely one way and hooked entirely the opposing way, since there would be breakages of the surface, which then could not operate aerodynamically. Furthermore, feathers have been found encased within amber (hardened resin), as shown in Fig. 6. The amber, by traditional dating mechanisms, is estimated to be 25 million years old, and yet the full barb system can be seen in some samples, indicating no difference in essence to modern feathers. 


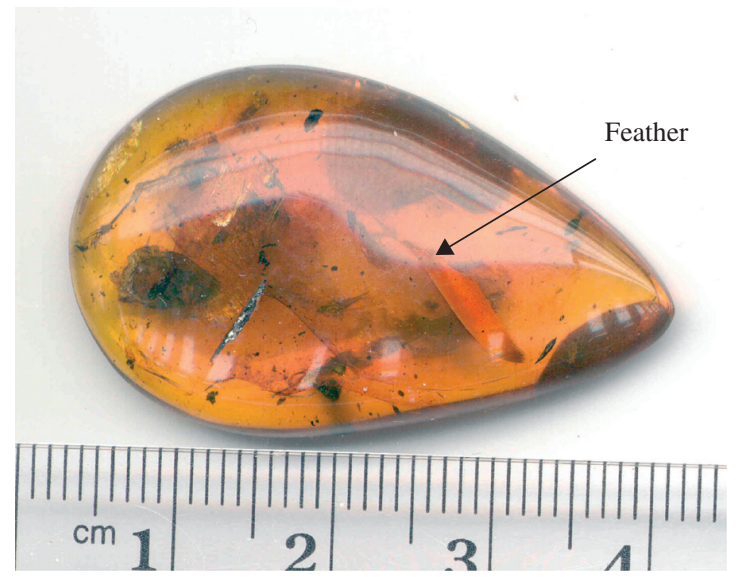

Figure 6: Pennaceous feather caught in Dominican amber (hardened resin) supposed to be 25 million years old by classical dating schemes. (This specimen from the Dominican Republic was originally for sale via the web. They usually sell for at least \$2000.)

\section{THE AVIAN LUNG}

3.1 Breathing systems of reptiles and that of birds

The other unique function in birds is the way they breathe. This is entirely different to both mammals and reptiles, which use a diaphragm and single pass ventilating apparatus, which brings the air to a halt before being exhaled at the second part of the cycle. Birds have a two-pass system where the air is in a continuous transit through the lung.

The oxygen exchange in the reptilian and mammalian lungs is provided by an end flow exchange system (see Fig. 7). The respiration takes place across the membranes of small balloon-like structures (called alveoli) attached to the branches of the bronchial passages. These alveoli inflate and deflate with inhalation and exhalation. In contrast to this, the bird lung (Fig. 8) is a parallel flow
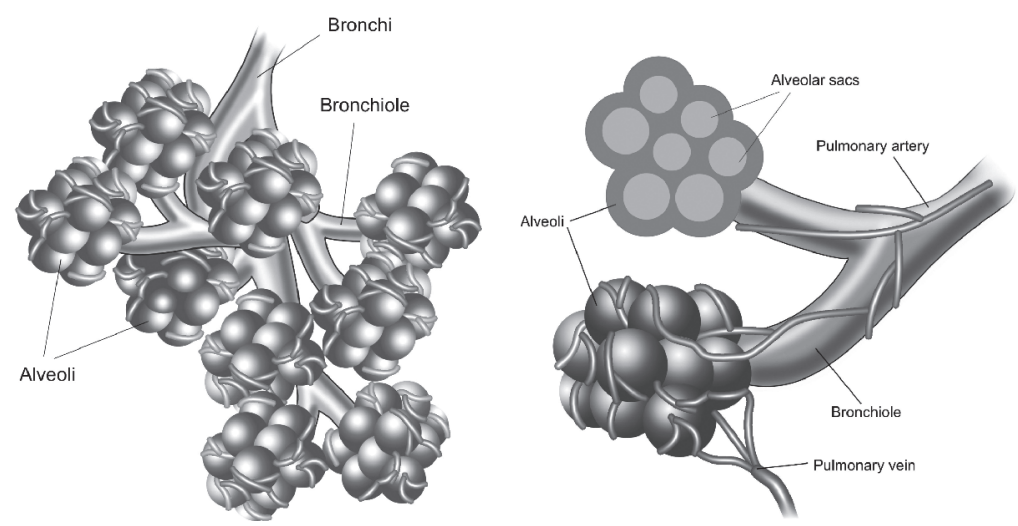

Figure 7: The end flow mass exchanger in mammalian and reptilian respiration. 


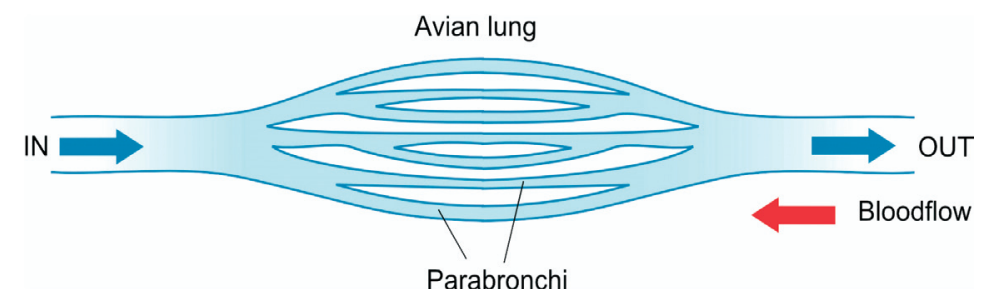

Figure 8: Idealised schematic of parallel counterflow mass exchange system in avian respiration.

system, where instead of alveoli, the bronchial passage breaks into parabronchi tubes such that oxygen is continuously flowing through the lung.

It is significant that such a mass exchange system is used for a bird, since the breathing of a bird is much faster than in a mammal or land-based reptile. It is well known that the most efficient mass exchange system for achieving the maximum gas exchange (by diffusion) across a membrane to a liquid for the minimum amount of material usage is to use a counterflow mass exchanger [33].

Not only is the mass exchange system entirely different for birds than for reptiles and mammals, but the circulatory pathways [34] are totally different in construction as well (Fig. 9). A bird has no diaphragm unlike mammals and reptiles. Instead, it uses the sternum (breastbone) to move air round the circulatory system. During inspiration, the sternum moves forward and downward with a combined movement of the vertebral ribs such that the pressure is lowered and the rear (posterior) and front (anterior) air sacs inflate in a definite sequence. Air from the trachea and bronchial pathways moves into the rear air sacs and, simultaneously, air from the lungs moves into the front air sacs. During expiration, the reverse happens. The sternum moves backward and the pressure is increased, causing the front and rear air sacs to inflate. Air from the rear sacs moves into the lungs and, simultaneously, air from the front sacs moves into the trachea and out of the body. Consequently, air always moves unidirectionally through the lungs with two cycles of inspiration and exhalation taking one packet of air through the system. The first inhalation takes air to the rear air sac. Then the first expiration takes that packet of air through the lung. The second inspiration then draws the same

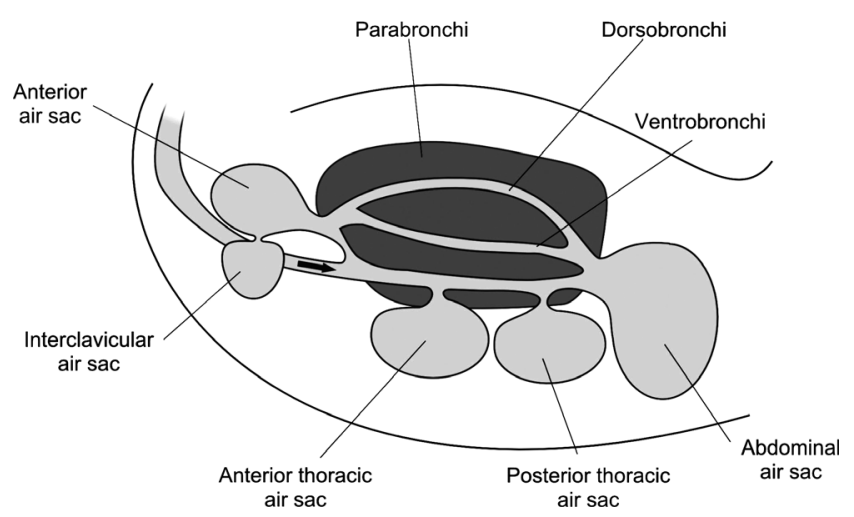

Figure 9: Diagrammatic representation of bird breathing system. 
packet of air into the front air sac, and finally the second expiration exhales this packet of air out of the trachea.

The sternum bone used for breathing is also central to the vital flight muscle arrangement. Across the keel of the sternum is the major pectoralis muscle, which powers the vital downstroke of a bird. But most important is also the smaller supracoracoideus muscle, which has a tendon that acts as a pulley by curving over and attaching to the main humerus (arm bone) from above (Fig. 10). The supracoracoideus muscle thus gives the power for the upstroke and also rotates the humerus at the peak of the upstroke. The multifunctioning arrangement of the sternum ensures that there is no wastage of weight and the breathing in flight is coupled with the wing dynamics.

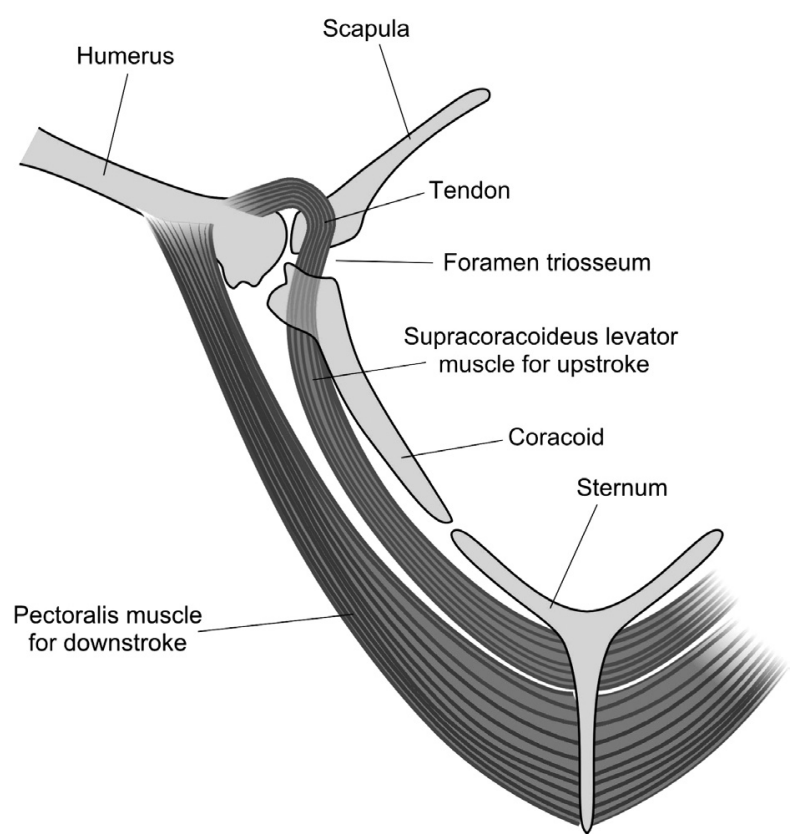

Figure 10: Supracoracoideus muscle and acrocoracoid arrangement in bird structure.

\subsection{Design features of the avian lung}

\subsubsection{Continuous flow counterflow mass exchanger}

The intricate system of breathing using the parabronchial gas exchange system is described in detail by Duncker [35]. The fine tubes of the parabronchial system are such that they could not be inflated; therefore, the notion that this system could have possibly appeared out of an alveoli balloon system is wishful thinking. Denton ([36], p. 361) has summarised this matter as follows:

the unique function and form of the avian lung necessitates a number of additional unique adaptations during avian development. As H.R. Dunker, one of the world's authorities in this field, explains, because first, the avian lung is fixed rigidly to the body wall and cannot therefore expand in volume and, second, because of the small diameter of the lung capillaries and the resulting high surface tension of any liquid within them, the avian lung cannot be inflated out of a collapsed state as happens in all other vertebrates after birth. The air capillaries are never 
collapsed as are the alveoli of other vertebrate species; rather, as they grow into the lung tissue, the parabronchi are from the beginning open tubes filled with either air or fluid.

For Denton ([36], p. 283) (following Kauffman [25]), the answer lies in some yet-to-be-understood, emergent self-organising group of processes in order to achieve such devices as the avian lung - he maintains that they do not fit with an explanation using natural selection and mutations. All accept that natural selection causes adaptation of existing organisms to environmental pressures. What is in debate is the power of such a process to cause entirely new function to arrive. Even among evolutionary biologists [37], there is an acknowledgement of the limitations of change possible from selective pressures. That the evidence of the fossils does not support gradual development was acknowledged by Gould who proposed the punctuated equilibrium hypothesis [38], where it was proposed that there was a speedy evolutionary development not captured by fossilisation. However, even if one does take the fossil evidence as the record of development, the evidence is in fact much more consistent with an ab initio design position - that the breathing mechanism of birds is in fact the product of intelligent design. Certainly, the considerations of the avian respiratory system show that this is a most reasonable deduction, even though Denton and many others search for alternatives of 'emerging self-organisation'.

\subsubsection{Parabronchial tubes and no diaphragm}

Of interest also is that the passages in the parabronchial pathways of the avian lung are so narrow that the air sacs could not operate in a filling and collapsing mode as would be required in some transitional creature. This is the very reason why the avian lung is indeed surrounded by air sacs so that there is a constant passage of air through the parabronchial tubes. Thus, there is no danger of deflation.

Furthermore, as the air in an avian lung is only ever travelling in one direction, there is no mixing of the air which has a greater proportion of oxygen with that which has a greater proportion of carbon dioxide. Consequently, the partial pressure of oxygen (and carbon dioxide) in the avian system is the same as in the outside environment and this leads to a further efficiency in the respiration system compared to the diaphragm system used in mammals and reptiles.

O'Connor and Claessens [39] have recently sought to argue that the avian lung was present in some theropod dinosaurs. This they have tried to infer from the bone design, which shows some evidence of having key cavities similar to bird bone structure. There may prove to be a similarity, but that there may have been a common breathing system is, of course, no proof of a taxonomical connection between birds and small theropods, any more so than a hypothetical connection of mammals with reptiles could be established simply on the basis of a common diaphragm ventilating respiratory system. The problem of the derivation of the avian lung at any stage is formidable. This applies wherever one attempts the transition - either in some ancestor to birds or in the transition to birds themselves. Ruben et al. [40] (and see also Quick and Ruben [41], particularly Figure 5 caption) state clearly the problem of any in-between respiratory system - the difficulty is fundamental and lies at the heart of the argument concerning design in nature. The development of an avian lung system from some ancestral breathing system brings with it insurmountable difficulties. Any attempt to find an evolutionary pathway involving gradual changes from an ancestral diaphragm breathing system to a breastbone bellows mechanism that a bird uses, meets severe obstacles [40]:

The earliest stages in the derivation of the avian abdominal air sac system from a diaphragmventilating ancestor would have necessitated selection for a diaphragmatic hernia in taxa transitional between theropods and birds. Such a debilitating condition would have immediately compromised the entire pulmonary ventilatory apparatus and seems unlikely to have been of any selective advantage. 
This shows that the basic thesis of an evolutionary connection between the two respiratory systems is incorrect.

Denton [42] summarises the issues even more explicitly for both the avian lung and the feather barb system of the previous section:

Just how such an utterly different respiratory system could have evolved gradually from the standard vertebrate design is fantastically difficult to envisage, especially bearing in mind that the maintenance of respiratory function is absolutely vital to the life of an organism to the extent that the slightest malfunction leads to death within minutes. Just as the feather cannot function as an organ of flight until the hooks and barbules are coadapted to fit together perfectly, so the avian lung cannot function as an organ of respiration until the parabronchi system which permeates it and the air sac system which guarantees the parabronchi their air supply are both highly developed and able to function together in a perfectly integrated manner.

\subsection{A note on the osteological evidence in birds}

The main arguments presented in this paper have focused on feathers and the uniqueness of the avian lung. It may be argued that the evidence then of bird evolution lies in the other features, particularly the osteological evidence - that is, from the bones of the fossils themselves. It should be pointed out that this evidence actually is always consistent as the main distinguishing features of birds. The furcula (wishbone) and sternum (breast) bones so prominent in living birds are also very evident in the fossils of birds similar to living birds today. Archaeopteryx has often been posed as a possible contender for a transition to birds. There are fossils of these creatures found in Bavaria in Germany. One well-preserved example is from the Solnhofen quarry. Examination of the skeletal structure of these fossils shows that this creature lacked the keeled sternum arrangement and the acrocoracoid process which provides the pulley around which the tendon of the supracoracoideus muscle runs (Fig. 10). Although it did have a furcula, the lack of keeled sternum and acrocoracoid process suggests that it flew by a similar technique to bats and may have been arboreal in habitat. This would be consistent with the evidence that unlike modern birds, Archaeopteryx has no air spaces in its bones, suggesting that it may have been a feathered reptile. In general, the creatures without neither furcula nor keeled sternum [such as the Chinese Liaoning shale dinosaur fossils (e.g. Sinornithosaurus)] are also the ones which clearly do not have the feathers either (as against extinct birds such as Hongshanornis longicresta which have both). In that it is now known that homologous structures are produced by different gene sequences in different species, any argument from homology relating apparent phenotype similarity of the pentadactyl forelimb of a therapod dinosaur to a bird is not a strong argument at the genotype level. Biologist John Randall [43] wrote:

The older textbooks on evolution make much of the idea of homology, pointing out the obvious resemblances between the skeletons of the limbs of different animals. Thus the 'pentadactyl' limb pattern is found in the arm of a man, the wing of a bird, and flipper of a whale - and this is held to indicate their common origin. Now if these various structures were transmitted by the same gene couples, varied from time to time by mutations and acted upon by environmental selection, the theory would make good sense. Unfortunately this is not the case. Homologous organs are now known to be produced by totally different gene complexes in the different species. The concept of homology in terms of similar genes handed on from a common ancestor has broken down .... 
In this context of homologous structures, it is important to note that Kimura [44] and indeed (some years before) Haldane [45] both agree that it is not possible to select for a large number of traits simultaneously due to the immense genetic cost at the phenotype level of such selective pressures [46].

Of importance to note also is that recent finds of parrots in the lower Eocene Fur formation in Denmark [47] are consistent with the design thesis and not consistent with the slow gradualism of Darwinian evolution. Furthermore, an earlier paper reporting a lower parrot jaw bone found in the Cretaceous layers of Wyoming [48], though regarded by many as misidentification, may in fact be genuine and again be consistent evidence with the design hypothesis.

\section{CONCLUSION}

In this paper, we have considered two examples of design in birds which defy explanation by gradual changes since to function at all, all the parts necessary for function must be there to begin with. As examples of irreducible complexity, they show that natural systems have intricate machinery which does not arise in a 'bottom up' approach, whereby some natural selective method of gaining smallscale changes could give the intermediary creature some advantage. This will not work since, first, there is no advantage unless all the parts of the new machine are available together and, second, in the case of the avian lung the intermediary creature would not be able to breathe, and there is little selective advantage if the creature is no longer alive.

As stated in the introduction, the possibility of an intelligent cause is both a valid scientific assumption, and borne out by the evidence itself. This approach suggests that there is a basic design of bird with furcula, keeled sternum, acrocoracoid process, air sac system, counterflow mass exchanger lung and feathers which have hooked and ridged barbules, which is ancestral and quite different to reptile design where these salient features are absent.

\section{REFERENCES}

[1] Dawkins, R., From introduction to issue called 'Darwin and Evolution', Natural History Magazine, American Museum of Natural History, November 2005.

[2] McIntosh, A.C., Functional information and entropy in living systems. Design and Nature III. Third International Conference on Design \& Nature: Comparing Design in Nature with Science and Engineering, 24-26 May 2006, Vol. 87 of WIT Transactions on Ecology and the Environment, ed. C.A. Brebbia, WIT Press, Wessex Institute of Technology: New Forest, pp. 115-126, 2006, ISBN: 1-84564-166-3. doi:10.1186/1742-4682-2-29

[3] Abel, D.L. \& Trevors, J.T., Three subsets of sequence complexity and their relevance to biopolymeric information. Theoretical Biology and Medical Modelling, 2, art. 29, 2005, http://www.tbiomed.com/content/2/1/29.

[4] An example would be Watson, D.M.S., Adaptation. Nature, 123 (sic Vol. 124) (10 August 1929), pp. 231-234, 1929. On p.233 he states 'The theory of evolution is a theory universally accepted not because it can be proved by logically coherent evidence to be true but because the only alternative, special creation, is clearly incredible.' Though it is true that Watson maintains this position because he refers to 'the collapse of alternative explanations', it is still an undeniable a priori assumption. It is quoted here to show that right from the outset the debate has been over assumptions and evidences. It is not just about evidences.

[5] Gould, S.J., Hen's Teeth and Horse's Toes. Norton: New York, pp. 254-255, 1994.

[6] Bonser, R.H.C., Saker, L. \& Jeronimidis, G., Toughness anisotropy in feather keratin. Journal of Materials Science, 39, pp. 2895-2896, 2004. See also web site of Richard Bonser at http://www.rdg.ac.uk/biomim/personal/richard/keratin.htm, which has a useful summary of the material properties of feathers (accessed March 2007). 
[7] Alexander, N.J., Comparison of $\alpha$ and $\beta$ keratin in reptiles. Cell and Tissue Research, 110(2), pp. 153-165, 1970.

[8] Yu, M., Yue, Z., Wu, P., Wu, D.-Y., Mayer, J.-A., Medina, M., Widelitz, R.B., Jiang, T.-X. \& Chuong, C.-M., The developmental biology of feather follicles. International Journal of Developmental Biology, 48, pp. 181-191, 2004. doi:10.1387/ijdb.15272383

[9] King, A.S. \& McLelland, J., Birds - Their Structure and Form, Bailliere Tindall: London, 1984.

[10] Burgess, S.C., Multi-functioning and multi-optimisation in feathers. International Journal of Design and Nature, 1(1), pp. 1-10, 2007. doi:10.2495/JDN-V1-N1-1-10

[11] Ji, Q., Norell, M.A., Gao, K.-Q., Ji, S.-A. \& Ren, D., The distribution of integumentary structures in a feathered dinosaur. Nature, 410, pp. 1084-1088, 2001. doi:10.1038/35074079

[12] Prum, R.O., Development and evolutionary origin of feathers. Journal of Experimental Zoology (Molecular and Developmental Evolution), 285(4), pp. 291-306, 1999. doi:10.1002/ (SICI) 1097-010X(19991215)285:4<291::AID-JEZ1>3.0.CO;2-9

[13] Xu, X., Zhou, Z.-H. \& Prum, R.O., Branched integumental structures in Sinornithosaurus and the origin of feathers. Nature, 410, pp. 200-204, 2001. See also http://www.nurseminerva. co.uk/adapt/feathers.htm for a summary (accessed August 2007).

[14] Christensen, P. \& Bonde, N., Body plumage in Archaeopteryx: a review, and new evidence from the Berlin specimen. Comptes Rendus Pale, 3, pp. 99-118, 2004. doi:10.1016/j.crpv.2003.12.001

[15] Xu, X., Zhou, Z., Wang, X., Kuang, X., Zhang, F. \& Du, X., Four-winged dinosaurs from China. Nature, 421(23), pp. 335-340, 2003. doi:10.1038/nature01342

[16] Chatterjee, S. \& Templin, R.J., Biplane wing planform and flight performance of the feathered dinosaur Microraptor gui. Proceedings of the National Academy of Sciences, 104(5), pp. 1576-1580, 2007. doi:10.1073/pnas.0609975104

[17] Zhou, Z. \& Zhang, F., Discovery of an ornithurine bird and its implication for early Cretaceous avian radiation. Proceedings of the National Academy of Sciences, 102(52), pp. 18998-19002, 2005. doi:10.1073/pnas.0507106102

[18] Yu, M., Wu, P., Widelitz, R.B. \& Chuong, C.-M., The morphogenesis of feathers. Nature, 420, pp. 308-312, 2002. doi:10.1038/nature01196

[19] Wu, P., Hou, H., Plikus, M., Hughes, M., Scehnet, J., Suksaweang, S., Widelitz, R.B., Jiang, T.-X. \& Chuong, C.-M., Evo-Devo of amniote integuments and appendages. International Journal of Developmental Biology, 48, pp. 249-270, 2004. doi:10.1387/ijdb.15272390

[20] Prigogine, I., Nicolis, G. \& Babloyantz, A., Thermodynamics of evolution (I). Physics Today, 25(11), pp. 23-28, 1972. doi:10.1063/1.3071090

[21] Prigogine, I., Nicolis, G. \& Babloyantz, A., Thermodynamics of evolution (II). Physics Today, 25(12), pp. 28-44, 1972. doi:10.1063/1.3071140

[22] Brooks, D.R. \& Wiley, E.O., Evolution as Entropy: Towards a Unified Theory of Biology, University of Chicago Press: Chicago and London, 1986.

[23] Wicken, J.S., Evolution, Thermodynamics, and Information: Extending the Darwinian Program, Oxford University Press: New York, 1987.

[24] Yockey, H., Information Theory and Molecular Biology, Cambridge University Press: New York, 1992.

[25] Kauffman, S.A., The origins of life: a new view (Chapter 7). Origins of Order - Selforganisation and Selection in Evolution, OUP: New York, pp. 287-341, 1993.

[26] Ball, P., The Self-made Tapestry - Pattern Formation in Nature, Oxford University Press: Oxford, New York, 2001.

[27] Murray, J.D., Mathematical Biology. II: Spatial Models and Biomedical Applications, 3rd edn, Springer-Verlag: New York, 2003. 
[28] Cruywagen, G.C., Maini, P.K. \& Murray, J.D., Sequential pattern formation in a model for skin morphogenesis. IMA Journal of Mathematics Applied in Medicine and Biology, 9, pp. 227-248, 1992. doi:10.1093/imammb/9.4.227

[29] Cruywagen, G.C., Maini, P.K. \& Murray, J.D., Sequential and synchronous skin pattern formation (Chapter 8). Experimental and Theoretical Advances in Biological Pattern Formation, ed. H.G. Othmer, Plenum: New York, 1993.

[30] Murray, J.D., Periodic patterns of feather germs (Section 6.5). Mathematical Biology. II: Spatial Models and Biomedical Applications, 3rd edn, Springer-Veralg: Berlin, pp. 345-349, 2003.

[31] McIntosh, A.C., Information and entropy - top-down or bottom-up development in living systems? International Journal of Design and Nature (in press), 2010.

[32] Twain, M., Life on the Mississippi, Penguin Classics: New York, p. 156, 1883. 'There is something fascinating about science. One gets such wholesale returns of conjecture out of such a trifling investment of fact.'

[33] Incropera, F.P., DeWitt, D.P., Bergman, D.L. \& Lavine, A.S., Fundamentals of Heat and Mass Transfer, 6th edn, Wiley: London, New York, 2006.

[34] A helpful summary of bird respiration is given at the following web site: http://people.eku.edu/ ritchisong/birdrespiration.html (accessed August 2007).

[35] Duncker, H.-R., Vertebrate lungs: structure, topography and mechanics: a comparative perspective of the progressive integration of respiratory system, locomotor apparatus and ontogenetic development. Respiratory Physiology \& Neurobiology, 144(2-3), pp. 111-124, 2004. doi:10.1016/j.resp.2004.07.020

[36] Denton, M.J., Nature's Destiny, Free Press: New York, 1998.

[37] Williams, G.C., Plan and Purpose in Nature: The Limits of Darwinian Evolution, Phoenix: London, 1997.

[38] Eldredge, N. \& Gould, S.J., Punctuated equilibria: an alternative to phyletic gradualism. Models in Paleobiology, ed. T.J.M. Schopf. Freeman Cooper: San Francisco, pp. 82-115, 1972.

[39] O'Connor, P.M. \& Claessens, L.P., Basic avian pulmonary design and flow-through ventilation in non-avian theropod dinosaurs. Nature, 436, pp. 253-256, 2005. doi:10.1038/nature03716

[40] Ruben, J.A., Jones, T.D., Geist, N.R. \& Hillenius, W.J., Lung structure and ventilation in Theropod Dinosaurs and early birds. Science, 278, pp. 1267-1270, 1997. doi:10.1126/science.278.5341.1267

[41] Quick, D.E. and Ruben, J.A., Cardio-pulmonary anatomy in theropod dinosaurs: implications from extant archosaurs, Journal of Morphology, doi: 10.1002/jmor.10752, 2009. doi:10.1002/ jmor.10752

[42] Denton, M.A., Evolution - A Theory in Crisis, Adler \& Adler: US, pp. 211-212, 1986.

[43] Randall, J.L., Parapsychology and the Nature of Life - A Scientific Appraisal, Sphere Books: Abacus, London, p. 210, 1975.

[44] Kimura, M., Neutral Theory of Molecular Evolution, Cambridge University Press: Cambridge, New York, 1983. See particularly p. 26.

[45] Haldane, J.B.S., The cost of natural selection. Journal of Genetics, 55, pp. 511-524, 1957. doi:10.1007/BF02984069

[46] Sanford, J.C., Genetic Entropy and the Mystery of the Genome, Ivan Press: New York, pp. 78-79, 2005.

[47] Waterhouse, D.M., Lindow, B.E.K., Zelenkov, N.V. \& Dyke, G.J., Two new parrots (psittaciformes) from the Lower Eocene Fur Formation of Denmark. Palaeontology, 51(3), pp. 575-582, 2008. doi:10.1111/j.1475-4983.2008.00777.x

[48] Stidham, T.A., A lower jaw from a Cretaceous parrot. Nature, 396, pp. 29-30, 1998. doi: $10.1038 / 23841$ 